\title{
Climate-driven increases in storm frequency simplify kelp forest food webs
}

\author{
JARRETT E. BYRNES*, DANIELC. REED*, BRADLEY J. CARDINALE†, \\ KYLE C. CAVANAUGH $\ddagger$ SALLY J. HOLBROOK§ and RUSSELL J. SCHMITT \\ *Marine Science Institute, University of California Santa Barbara, Santa Barbara, CA 93106, USA, †School of Natural Resources $\mathcal{E}$ \\ Environment, University of Michigan, Ann Arbor, MI 48109, USA, $\ddagger$ Earth Research Institute, University of California \\ Santa Barbara, Santa Barbara, CA 93106, USA, §Department of Ecology, Evolution, and Marine Biology, University of California \\ Santa Barbara, Santa Barbara, CA 93106, USA
}

\begin{abstract}
Climate models predict a dramatic increase in the annual frequency and severity of extreme weather events during the next century. Here we show that increases in the annual frequency of severe storms lead to a decrease in the diversity and complexity of food webs of giant kelp forests, one of the most productive habitats on Earth. We demonstrate this by linking natural variation in storms with measured changes in kelp forest food web structure in the Santa Barbara Channel using structural equation modeling (SEM). We then match predictions from statistical models to results from a multiyear kelp removal experiment designed to simulate frequent large storms. Both SEM models and experiments agree: if large storms remain at their current annual frequency (roughly one major kelp-removing storm every 3.5 years), periodic storms help maintain the complexity of kelp forest food webs. However, if large storms increase in annual frequency and begin to occur year after year, kelp forest food webs become less diverse and complex as species go locally extinct. The loss of complexity occurs primarily due to decreases in the diversity and complexity of higher trophic levels. Our findings demonstrate that shifts in climate-driven disturbances that affect foundation species are likely to have impacts that cascade through entire ecosystems.
\end{abstract}

Keywords: climate change, disturbance, food web, kelp forest, network theory, structural equation modeling

Received 3 September 2010; revised version received 19 January 2011 and accepted 24 January 2011

\section{Introduction}

Periodic disturbances are a natural component of almost every ecosystem, and many ecological models predict that the mortalities imposed by occasional disturbances can be vital for maintaining biological diversity as well as renewing essential nutrients. However, many of these same models also predict a decrease in diversity when the frequency or severity of disturbances becomes too great (Connell, 1978). Such predictions are important given that most climate change models show that the future will be characterized by increases in the frequency, and possibly severity, of many forms of large abiotic disturbances across the globe (Easterling et al., 2000; Meehl et al., 2000, 2007).

The consequences of increases in disturbance frequency for the diversity and complexity of an entire ecosystem are far from clear, however. Several decades of research characterizing how disturbance can influence species diversity have yielded no strong consensus

Correspondence: Present address: Jarrett E. Byrnes, National Center for Ecological Analysis and Synthesis, 735 State Street, Suite 300, Santa Barbara, CA, USA, e-mail: byrnes@nceas.ucsb.edu
(Mackey \& Currie, 2001; Hughes et al., 2007). In large part, this is because the theoretical foundations of most disturbance-diversity models do not incorporate multiple trophic levels (but see Wootton, 1998). These models also do not capture changes in the patterns of feeding links between species within an ecosystem - the structure of its food web. More general theories and observational analyses of food webs have concluded that the stress and stochasticity indicative of disturbance should simplify and shorten food webs (Briand, 1983; Menge \& Sutherland, 1987). The evidence for direct impacts of disturbance on food chain length is equivocal, however (e.g., Pimm \& Kitching, 1987; Marks et al., 2000; Walters \& Post, 2008; McHugh et al., 2010). In contrast, food web complexity has routinely been linked to the input of energy into an ecosystem (Oksanen et al., 1981; Schoener, 1989; Thompson \& Townsend, 1999), habitat structure (Briand \& Cohen, 1987; Thompson \& Townsend, 2005), habitat heterogeneity (Walters \& Post, 2008), and ecosystem size (Schoener, 1989; Post et al., 2000) all of which can be altered by disturbance. Thus, the indirect impacts on food webs of disturbances driven by climate change are likely to be more prominent than the direct impacts. 
Disturbance-driven changes in food web structure affect ecosystem stability and function. For example, decreases in species richness at any one trophic level can alter primary production, nutrient cycling, and predator-prey dynamics (Cardinale et al., 2006). Simultaneous changes in diversity at multiple trophic levels can have complex and often unpredictable consequences for both primary and secondary production (Gamfeldt et al., 2005; Douglass et al., 2008). Furthermore, alteration of the network structure of food webs could impact the resilience of ecosystems to future human impacts. Reductions in the complexity of food webs have been suggested to decrease both their long-term stability and increase the probability of cascading extinctions if food webs are further perturbed (McCann et al., 1998; Dunne et al., 2002; Roopnarine et al., 2007; Ling et al., 2009). Disturbances caused by climate change might therefore affect the function and stability of a broad variety of ecosystems by altering their food web structure.

In the Eastern Pacific, climate records show that the annual frequency of years with large waves driven by winter storms has increased over the last 60 years (Graham \& Diaz, 2001; Bromirski et al., 2003; Ruggiero et al., 2010). This increase in the annual frequency of large storm-driven waves could have detrimental effects on coastal ecosystems dominated by the giant kelp Macrocystis pyrifera, which is a foundational species that provides habitat and energy to fuel a highly complex and productive food web (Dayton, 1985; Graham, 2004; Reed \& Brzezinski, 2009). Large waves associated with winter storms often tear out giant kelp, reducing the abundance of this habitat forming species. These reductions likely result in changes to the structure of the associated kelp forest food web (e.g., through changes in three-dimensional habitat structure as in Briand \& Cohen, 1987), yet changes beyond associated sessile species (Arkema et al., 2009) have yet to be documented. Giant kelp in southern California, for example, typically recovers from severe storms within 2 years, faster than the current frequency of one severe storm every 3.5 years (Graham et al., 1997). If large storms begin to occur annually, though, food web structure may be greatly altered.

Here we show that an increase in the annual frequency of severe kelp-removing storms simplifies food webs in the kelp forests of southern California. To understand how changes in wave disturbances from winter storms influence kelp forest food webs, we examined the direct and indirect mechanisms by which large storms influence kelp forest food web structure using structural equation modeling (SEM; Bollen, 1989). To fit models, we used data from 35 sites distributed across nine rocky reefs in the Santa Barbara Channel from 2002 through 2009. Food webs from these reefs comprised 217 species with $\sim 1800$ possible feeding links documented in the literature. We then used parameterized models to simulate the effects of different disturbance frequencies on food web structure, and verified these predictions with a multiyear field experiment that mimicked kelp loss from large storms.

\section{Methods}

To understand the importance of storms on kelp forest food web structure, we first modeled the effect of large wave disturbances caused by winter storms on food webs using 8 years of kelp forest community data. To evaluate the effect of these large wave disturbance events, we constructed structural equation models that examined the direct and indirect paths leading from storms and kelp to food web structure and complexity (i.e., topology). SEMs described how maximum winter wave disturbance, kelp abundance before storms, and kelp abundance both immediately and several months after winter storms (i.e., spring and summer) influence species richness and four metrics of food web structure derived from network theory (Vermaat et al., 2009): the mean number of feeding links per species (i.e., linkage density), consumer diet breadth (i.e., the standard deviation in the number of prey per consumer), and the mean and variation (i.e., standard deviation) in food chain length from basal species to top predators. Additional SEMs considered the richness of species in different trophic or functional groups. We used the following data to fit these models: (1) benthic data from the Santa Barbara Coastal Long-Term Ecological Research (SBC LTER) project's summer kelp forest community surveys, (2) information from the literature describing the food web of all species recorded in the SBC LTER surveys, (3) measurements of winter wave height and period from the Coastal Data Information Project (http:// cdip.ucsd.edu), and (4) measurements of kelp surface canopy immediately following winter storms from Landsat imagery.

To evaluate and verify our predictions regarding the effects of increases in the annual frequency of severe storms, we used parameterized models to simulate changes in food web structure under three different storm scenarios: (1) minimal storm disturbance, (2) 1 year of strong storms, and (3) multiple consecutive years of strong storms that remove all kelp from a reef. We then compared these predictions to results from a field experiment simulating annual storm disturbances on kelp forests.

\section{Kelp forest community surveys}

Annual kelp forest community surveys were conducted in late July-early August as part of the SBC LTER project (http:// sbc.lternet.edu). At each site, divers laid a $40 \mathrm{~m}$ graduated tape between permanently marked points. We counted all giant kelp fronds in the $2 \mathrm{~m} \times 40 \mathrm{~m}$ area around this transect and $\log (x+1)$ transformed the data for analysis in order to facilitate model fitting. The diversity of invertebrates and understory macroalgae was assessed in six $1 \mathrm{~m}^{2}$ quadrats, four $2 \mathrm{~m} \times 20 \mathrm{~m}$ band transects, or 80 uniformly spaced points along the transect, depending on the species. Reef fish diversity was assessed in a $2 \mathrm{~m}$ wide swath centered along the transect that extended $2 \mathrm{~m}$ off the bottom. We measured the cover of rocky 
reef along transects as the percentage of the 80 uniformly spaced points along transects that intersected rock (as opposed to sand).

\section{Food web construction}

In order to assemble a food web for all species sampled in the SBC LTER summer kelp forest community surveys, we conducted a literature review on diets and consumptive habits of target species. After obtaining information from several general reviews of the natural history of kelp forest fish and invertebrates (Limbaugh, 1955; Quast, 1968; Foster \& Schiel, 1985; Hobson \& Chess, 1986, 2001) we performed a search for each species using ISI Web of Science, Google Scholar, Avano, and Aquatic Commons. Each species name was searched with the additional keywords of 'diet ${ }^{* \prime}$, 'predator', 'prey', 'gut content $^{* \prime}$, and 'feeding' (asterisks used to expand search terms). In addition, we searched these five keywords in thesis, grey literature, and student report databases at the Cadet Hand Library at the Bodega Marine Laboratory, the Moss Landing Marine Laboratory Library, the Miller Library at the Hopkins Marine Station, and the Scripps Institute of Oceanography Library. Only feeding observations from studies that showed direct consumption (e.g., either a feeding observation in the field, gut contents, or lab preference study) or provided strong evidence of a direct feeding relationship between two taxa were used. Our final food web was revised and verified after consultation with several experts in the field of kelp forest community ecology (see supporting information Appendix S1 for explicit protocols, full citations, and experts consulted).

\section{Wave disturbance measurements}

We quantified disturbance from storms as the maximum horizontal orbital velocity of waves in the winter. This measurement integrates both swell height and period and corresponds to the greatest stress on kelp fronds exerted by waves during severe winter storms (Graham et al., 1997). It should therefore correlate with the largest amount of potential damage done to giant kelp by winter storms in a given year. Maximum winter horizontal orbital velocity measurements at each transect were calculated by taking swell height and period measurements from the Coastal Data Information Project's swell model (http://cdip.ucsd.edu) and transforming them using equations from linear wave theory (see Denny et al., 2004 for equations). Measurements were taken from the closest modeled location to a given transect (typically $<100 \mathrm{~m}$ away). We took the maximum value for the period from December through March, the time of maximum storm intensity in the Santa Barbara Channel.

\section{Postdisturbance spring kelp canopy measurements}

The amount of disturbance experienced by a kelp forest is not necessarily reflected by kelp density in the summer following a large storm. Giant kelp can recover within months, and often disturbed forests are populated by new Macrocystis recruits that can form a canopy by the following summer. To determine how much disturbance a forest experienced, we needed a measurement of kelp canopy cover in the spring, immediately after disturbance and before regrowth. Incorporating spring canopy into our models also provided us with an indicator of subsurface irradiance during spring, which is the time of peak recruitment and growth for many algal species (Dayton et al., 1984; Reed \& Foster, 1984; Reed et al., 1996, 2008).

We used images from the Landsat 5 satellite to estimate the percent of kelp canopy cover along each transect in the spring. The Landsat 5 thematic mapper sensor has acquired $30 \mathrm{~m}$ spatial resolution multispectral imagery nearly continuously from 1984 to the present with a 16-day repeat cycle. During each year that benthic surveys were conducted, we acquired one to three cloud-free Landsat images taken between March and May. Each Landsat image contained all of the benthic survey locations. Landsat images were geometrically corrected using ground control points and a digital elevation model to achieve a scene-to-scene registration accuracy $<7.3 \mathrm{~m}$ (Lee et al., 2004). All images in the time series were standardized to relative reflectance using the empirical line correction method to correct for atmospheric effects (Furby \& Campbell, 2001; Baugh \& Groeneveld, 2008).

In order to measure the amount of kelp canopy in each satellite image we classified the nearshore regions using Spectral Mixture Analysis, a technique based on the assumption that the reflectance of a pixel can be modeled as a linear combination of $N$ spectral endmembers weighted by the fraction of each endmember (Adams et al., 1993; Roberts et al., 1998). We modeled each pixel as a combination of water and kelp canopy and thus transformed the satellite image into maps of a canopy index that represented the percent of each pixel that was covered by kelp. In years where we had multiple spring images, we averaged the canopy index of each pixel across all of the available image dates. To estimate the amount of spring kelp canopy present each year at each benthic survey transect, we summed and $\log (x+1)$ transformed the kelp canopy indices of all pixels within $150 \mathrm{~m}$ of the center of each transect.

\section{Structural equation models}

Disturbance from waves can affect the structure and complexity of kelp forest food webs through a wide variety of direct and indirect pathways. We therefore utilized SEM to simultaneously examine each of these pathways while accounting for correlations between multiple response variables (Bollen, 1989). All models were fit using the sem package in $\mathrm{R}$ (Fox, 2006). Because our data violated the SEM assumption of multivariate normality (multivariate Shapiro-Wilk's test, $P<0.001$ ), we calculated corrected fit indices and path coefficient standard errors using the sem.additions package (Byrnes, 2010).

The amount of disturbance experienced by a forest depends both on the amount of kelp initially present and the strength of the wave disturbance. We incorporated this in our models with an interaction effect between wave disturbance and kelp abundance in the previous year. We fit models with both a centered and noncentered interaction term. Model results were the same, and we therefore present estimates from the noncentered analysis for easier interpretation (i.e., the additive paths of waves and kelp in the previous year reflect their 
correlation with response variables when the other predictor is at 0 , rather than at its mean value). We initially fit models with a path from the wave $\times$ kelp interaction to all variables in the model, but only found a strong effect of the interaction on spring kelp canopy. As the amount of spring canopy remaining reflected the amount of disturbance experienced by a forest, we also evaluated whether the applied or realized amount of disturbance was a better predictor of food web topology. We compared models with a path between wave disturbance and topological variables vs. models without these paths using a Satorra-Bentler corrected likelihood ratio $\chi^{2}$-test. When there was no effect $(P \geq 0.05)$ of dropping the wave $\rightarrow$ topology path, we removed it.

The state of a kelp forest in the previous year can have a large effect on community structure in the current year. The previous year's kelp density can affect the current year's kelp abundance, and the recruitment, growth, and survival of a wide variety of species. We therefore included paths from the previous year's kelp density to all response variables. We also evaluated models that incorporated lagged predictors of all endogenous variables. The results of these models were qualitatively similar, but increased the variability of some coefficient estimates. We therefore only present models using a lagged kelp abundance variable.

Models that examined the effect of wave disturbance on food web topology (i.e., network structure metrics) all included species richness as a response variable. Richness was positively correlated with nearly all measures of food web topology. As there is no clear theory relating topological variables to one another, we fit a sequence of models, each including kelp, wave disturbance, and species richness, but varying the final topological variable of interest. We considered using a latent variable for topology, but preliminary confirmatory factor analyses revealed that there was little shared variation between different metrics of food web topology, making it difficult to define a clear variable to represent 'topology' per se.

We examined how disturbance affected the richness of specific groups of species to determine the meaning behind changes in metrics of food web topology. We constructed two different models for this purpose, each with a structure similar to the models used to examine topology. The first model looked at changes in the richness of the two lowest trophic groups: resource species (i.e., algae + sessile invertebrates) and primary consumers (i.e., species that feed directly on resource species). We initially incorporated a bi-directional feedback between resource species and primary consumers into this model, but found that only the resource $\rightarrow$ consumer path had strong support $(P<0.001)$. We therefore refit the model without the consumer $\rightarrow$ resource path to avoid any potential confounding effects of a misspecified feedback. The second model that we constructed examined changes in the richness of species categorized into three different functional groups: algae, sessile invertebrates, and all mobile species. There is little causal evidence that richness of any one of these functional groups per se influences the richness of another functional group, and yet it is likely that multiple extrinsic factors lead to positive correlations between the richness of different groups. We therefore allowed the richness of these three taxonomic groups to freely covary.
Total kelp abundance along transects varied by three orders of magnitude. Therefore, in order to facilitate model fitting, kelp densities were $\log (x+1)$ transformed. While the maximum likelihood fitting criterion is scale-free (Bollen, 1989), the difference in the orders of magnitude between variables made it difficult for likelihood algorithms to converge on a solution when kelp densities remained untransformed. All models also included cover of rocky reef, as some reefs were periodically covered in sand, creating different communities.

\section{Simulations}

Because we were interested in how the effects of different disturbance regimes influenced food web topology, we translated our SEM results into systems of linear equations for simulation analyses. For each model, we excluded paths without strong support $(P>0.05)$, and used linear regressions to estimate intercepts. We then performed 10000 simulations for each response variable using random draws for each coefficient based on their estimated mean and standard error (Gelman \& Hill, 2006). For each draw, we calculated response variables under three scenarios: (1) a dense kelp forest (1000 fronds per $80 \mathrm{~m}^{2}$ transect) experiencing minimal wave disturbance (maximum winter horizontal orbital velocity of $0.41 \mathrm{~m} \mathrm{~s}^{-1}$, the minimum observed in our data); (2) a dense kelp forest experiencing the maximum observed disturbance $\left(2.31 \mathrm{~m} \mathrm{~s}^{-1}\right)$; and (3) a reef that previously has had all kelp removed by successive years of maximum strength disturbances ( 0 fronds per transect; simulation analysis estimates kelp will plateau at $\sim 50$ fronds per transect after 6 years, however, 0 is included in the $95 \%$ confidence interval of this estimate) experiencing yet another year at maximum levels of disturbance. We examined the difference between scenarios 1 and 2 to evaluate the probable effects of a single disturbance. We examined the difference between the second and third scenarios to evaluate the effects of one vs. multiple consecutive years of disturbance.

\section{Long-term kelp removal experiment}

To experimentally examine the effects of multiple consecutive years of kelp removal, we established paired $2000 \mathrm{~m}^{2}$ plots at four reefs and removed giant kelp from one of the plots at each reef in winter (i.e., January) 2008 and 2009. Before removing kelp, we counted it along $40 \mathrm{~m} \times 2 \mathrm{~m}$ transects centered within each plot and then resurveyed all transects in March of 2008 and 2009 to assess winter kelp loss. Transects were surveyed for algae, invertebrates and fish in the summers of 2008 and 2009 using the same sampling protocols used in the annual kelp forest community surveys. We fit separate regressions relating kelp loss to response variables for both years and compared the slopes between years with $t$-tests.

\section{Results}

\section{Structural equation models}

Our SEM results show that the spring canopy of a formerly dense kelp bed will be reduced by strong winter wave disturbance; this leads to an increase in 
Table $1 \chi^{2}$ likelihood ratio tests examining fit of models to observed covariance matrices and difference between models with vs. without a waves $\rightarrow$ topological variable path

\begin{tabular}{|c|c|c|c|c|c|c|c|c|}
\hline Model & $N$ & $\begin{array}{l}\text { Model } \\
\chi^{2}\end{array}$ & $\mathrm{df}$ & $\begin{array}{l}\text { Corrected } \\
\chi^{2}\end{array}$ & $P$ & $\begin{array}{l}\text { Likelihood ratio } \chi^{2} \\
\text { comparison for } \\
\text { inclusion of wave } \rightarrow \\
\text { topology path }\end{array}$ & $\begin{array}{l}\text { Difference } \\
\text { in } \mathrm{df}\end{array}$ & $P$ \\
\hline Linkage density & 253 & 9.282 & 5 & 1.640 & 0.896 & 4.080 & 2 & 0.130 \\
\hline Variation in consumer diet breadth & 252 & 5.912 & 5 & 1.067 & 0.957 & 2.011 & 2 & 0.366 \\
\hline Average \# links between two species & 253 & 6.825 & 5 & 1.229 & 0.942 & 1.794 & 2 & 0.408 \\
\hline Average food chain length & 253 & 7.611 & 5 & 1.369 & 0.928 & 2.586 & 2 & 0.274 \\
\hline Consumer-resource richness & 253 & 7.666 & 5 & 1.396 & 0.925 & 2.354 & 2 & 0.308 \\
\hline Functional group richness & 253 & 5.323 & 5 & 0.811 & 0.937 & 9.917 & 3 & 0.019 \\
\hline
\end{tabular}

We report both the uncorrected and Satorra-Bentler corrected $\chi^{2}$-statistics for model fit. For model fit, $P \geq 0.05$ indicates that fitted models produce covariance matrices between variables that are not strongly different from observed values (i.e., an indicator of adequate fit). Similarly, results for tests evaluating the inclusion of waves with a $P \geq 0.05$ indicate no effect on model fit of removing direct paths from waves to topology. Models where no direct path was supported were refit without this direct path.

species richness and the complexity of food webs. However, when kelp is already sparse, waves have little effect, and the net effect on food webs is to decrease complexity. For all SEM analyses, the covariance matrices produced model fits that were not statistically different from their observed covariance matrices (Table 1, columns 3-6), indicating an adequate model fit. Corrected likelihood-ratio $\chi^{2}$-tests showed that removing paths from waves to topological variables did not affect fit in any models except the functional group richness model (Table 1, last three columns). Hence, direct wave $\rightarrow$ topology paths were dropped for the analyses of all models except this last functional group model. All SEM results for models examining paths between waves and food web structure were relatively similar. As such, for models examining food web structure, only the linkage density results (Fig. 1) are discussed in detail, except where other models differed (see supporting information Table S2 for detailed coefficient results for all models). On average, SEMs explained $27 \%$ of the variation in topological response variables, although results varied by response type (Table 2). Given the large number of additional influences on response variables (e.g., oceanographic influences, sea urchin grazing, and other sources of local variability), we judged this explanatory power sufficient for further analyses.

When large amounts of kelp were present, 1 year of large wave disturbance decreased kelp abundance and increased food web complexity (Fig. 1). All SEMs suggest that the effect of waves on kelp was stronger when more kelp was present (i.e., wave $\times$ kelp interaction, see Fig. 1 and Table S2 for coefficient estimates and statistical tests). Wave disturbance had no effect in the absence of kelp, whereas there was a strong positive effect of kelp in the previous year on the spring canopy in the absence of waves. Spring kelp canopy was positively related to summer kelp density, but had a negative direct relationship with summer species richness (Fig. 1). Summer kelp density was linked to higher summer species richness. The amount of kelp remaining in the spring after winter storms therefore had opposing direct and indirect effects on species richness. However, the negative direct path from spring kelp had a larger effect than its positive indirect path (Fig. 1: spring kelp $\rightarrow$ species richness standardized path coefficient $=-0.23$ vs. spring kelp $\rightarrow$ summer kelp $\rightarrow$ species richness standardized path coefficient $=0.11$ ). Hence, a dense spring kelp canopy appeared to decrease species richness in the summer and its removal by waves therefore stimulates species richness. Richness was positively related to all metrics of food web topology (Fig. 1 for linkage density and Table S2 for all other metrics). Neither the spring kelp canopy or kelp abundance in the summer ever influenced additional metrics of food web structure $(P<0.05)$, except for variation in consumer diet, which decreased with greater spring canopy (Table S2).

SEMs examining trophic and functional groups revealed the mechanisms driving changes in species richness and food web structure. Changes in spring kelp canopy appeared to affect the richness of resource species (Fig. 2, supporting information Table S2 for detailed coefficient results). As with total species richness, the negative direct effect was stronger than the positive indirect effect. This increase in resource species richness led to an accompanying increase in consumer species richness. The functional group results (Fig. 3) indicate that the response of species richness to a single year of strong wave disturbance was driven by in- 


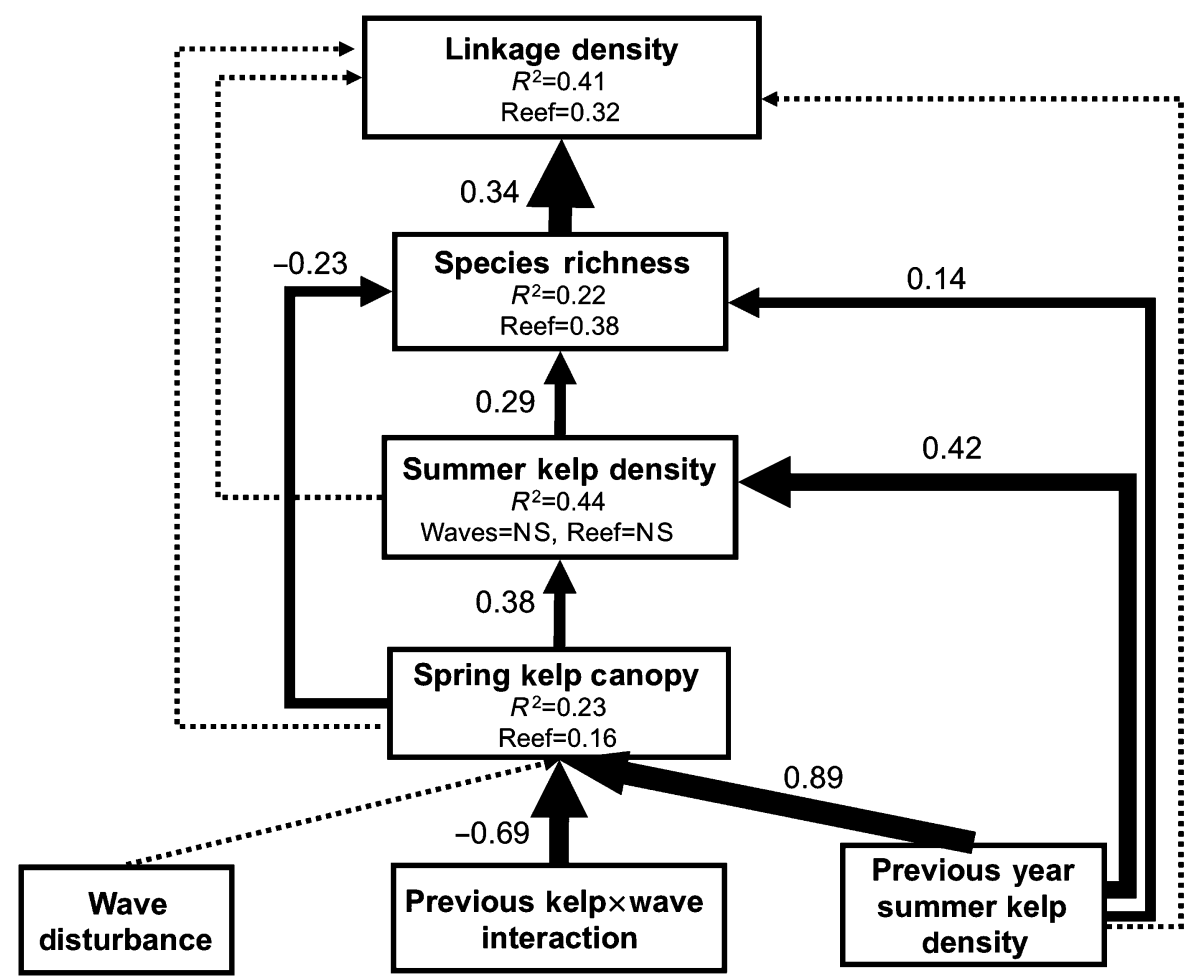

Fig. 1 Path diagrams showing how species richness and linkage density are associated with winter wave disturbance from storms and the abundance of kelp in the previous year. Results are from a fitted structural equation model that adequately reproduces the observed covariance matrix. Solid paths are statistically different from 0 at $P \leq 0.05$. Dashed paths are not. Path widths are proportional to standardized regression coefficients (shown next to each path), and only paths with strong support $(P \leq 0.05)$ are shown. $R^{2}=1-$ (residual variance/observed variance) for each variable. For clarity, some path coefficients are included in variable boxes rather than being drawn directly on the diagram (e.g., waves $\rightarrow$ summer kelp). The standardized coefficient between reef cover and each variable is also included in variable boxes rather than being drawn directly. Note the interaction between the previous year's summer kelp cover and wave disturbance, revealing that disturbance becomes minimal if no kelp is present to be removed.

creases in algal species richness due directly and indirectly to waves outweighing decreases in both sessile invertebrate and mobile species richness. The contrasting patterns of increases in consumer species richness (Fig. 2) but a net decrease in the richness of all mobile species (Fig. 3) in response to 1 year of waves appears to drive the changes in food chain length and average path length between the species, as food webs are simplified and omnivory and intraguild interactions are reduced.

Overall, the results from our models suggest that a single year of strong waves driven by storms striking a dense kelp forest tends to increase the complexity of the food web. However, the amount of kelp in the previous year has strong effects on food web structure. Kelp in the previous year directly increased summer kelp density, total species richness, and the species richness of all trophic and functional groups (paths on the right side of Figs. 1-3). With respect to topological variables, the previous year's kelp abundance had a direct, positive influence on diet variation. However, all other metrics were impacted indirectly via changes in species rich- ness. Therefore, while 1 year of strong wave disturbance may increase the diversity and complexity of a food web, the effects of deforestation by large storm-driven waves occurring multiple years in a row, at more frequent intervals than necessary for a kelp forest to recover, are likely quite different. These changes were clarified by simulation analyses.

\section{Simulations}

Results from SEMs were borne out in simulations (Table 2 ), and simulations showed that multiple consecutive years of large wave disturbances simplify kelp forest food webs. Complexity was greater in forests subjected to 1 year of large waves compared with those subjected to the minimum level of observed wave disturbance. In this comparison, resource, consumer, and algal species richness were all higher, and sessile and mobile species richness were lower in the wave disturbed simulation. In contrast, simulations comparing the consequences of 1 year vs. multiple successive years of wave disturbance 


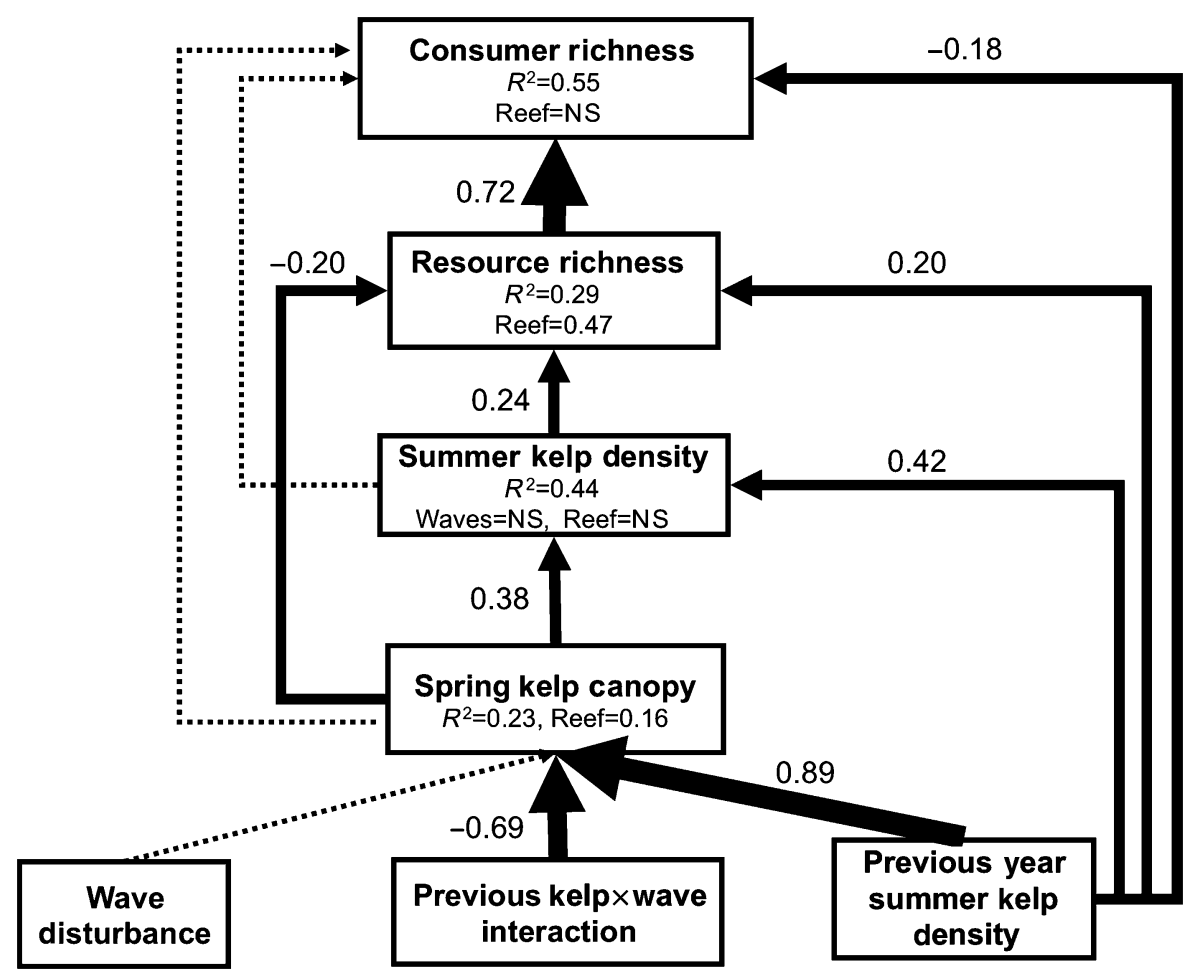

Fig. 2 Path diagrams showing how primary consumer and resource species are associated with winter wave disturbance from storms and the abundance of kelp in the previous year. Results are from a fitted structural equation model that adequately reproduces the observed covariance matrix. Solid paths are statistically different from 0 at $P \leq 0.05$. Dashed paths are not. Path widths are proportional to standardized regression coefficients (shown next to each path), and only paths with strong support $(P \leq 0.05)$ are shown. $R^{2}=1$-(residual variance/observed variance) for each variable. For clarity, some path coefficients are included in variable boxes rather than being drawn directly on the diagram (e.g., waves $\rightarrow$ summer kelp). The standardized coefficient between reef cover and each variable is also included in variable boxes rather than being drawn directly. Note that a similar model was fit including a consumer $\rightarrow$ resource path. This path was not supported, and was removed in order to allow for a more accurate assessment of the resource $\rightarrow$ consumer path.

(i.e., high disturbance and dense kelp vs. high disturbance and no kelp) showed a large decrease in all metrics of food web complexity that we evaluated after multiple consecutive years of disturbance. This is caused largely by the high relative importance of the previous state of a kelp forest shown in SEM analyses. All metrics of food web complexity and species richness in all functional groups were lower in the no kelp-high wave disturbance simulation compared with the dense kelp-high wave disturbance simulation (i.e., all values in the third column of Table 2 are negative). While resource species richness also declined, the results were within one standard deviation of 0 , indicating that it may stay constant. Overall, when kelp forests are subjected to repeated large wave disturbances in successive years, food web complexity declines due to the loss of giant kelp. The average species has fewer links to other species, and there is less variation in diet breadth among species. Notably, both the average food chain length and average number of feeding links between any two species also decrease, indicating that food webs begin to collapse and support fewer trophic levels.

\section{Long-term kelp removal experiment}

Results from 2 years of our $2000 \mathrm{~m}^{2}$ kelp removal experiment matched many of the qualitative trends evident from the structural equation models and resulting simulations. Based on our SEM and simulation results, we predict that large disturbances should generate rich, complex food webs in the first year of removal, but that this effect should decrease over time as the disturbances to a kelp forest are repeated in multiple, successive years. Consistent with this prediction, we observed higher species richness in summer following the first year of kelp removal (2008) along transects where more kelp was removed (Fig. 4, slope $=0.027 \pm 0.008 \mathrm{SE}, F=10.855, P=0.017$ ). Importantly, the slope of the relationship between summer 


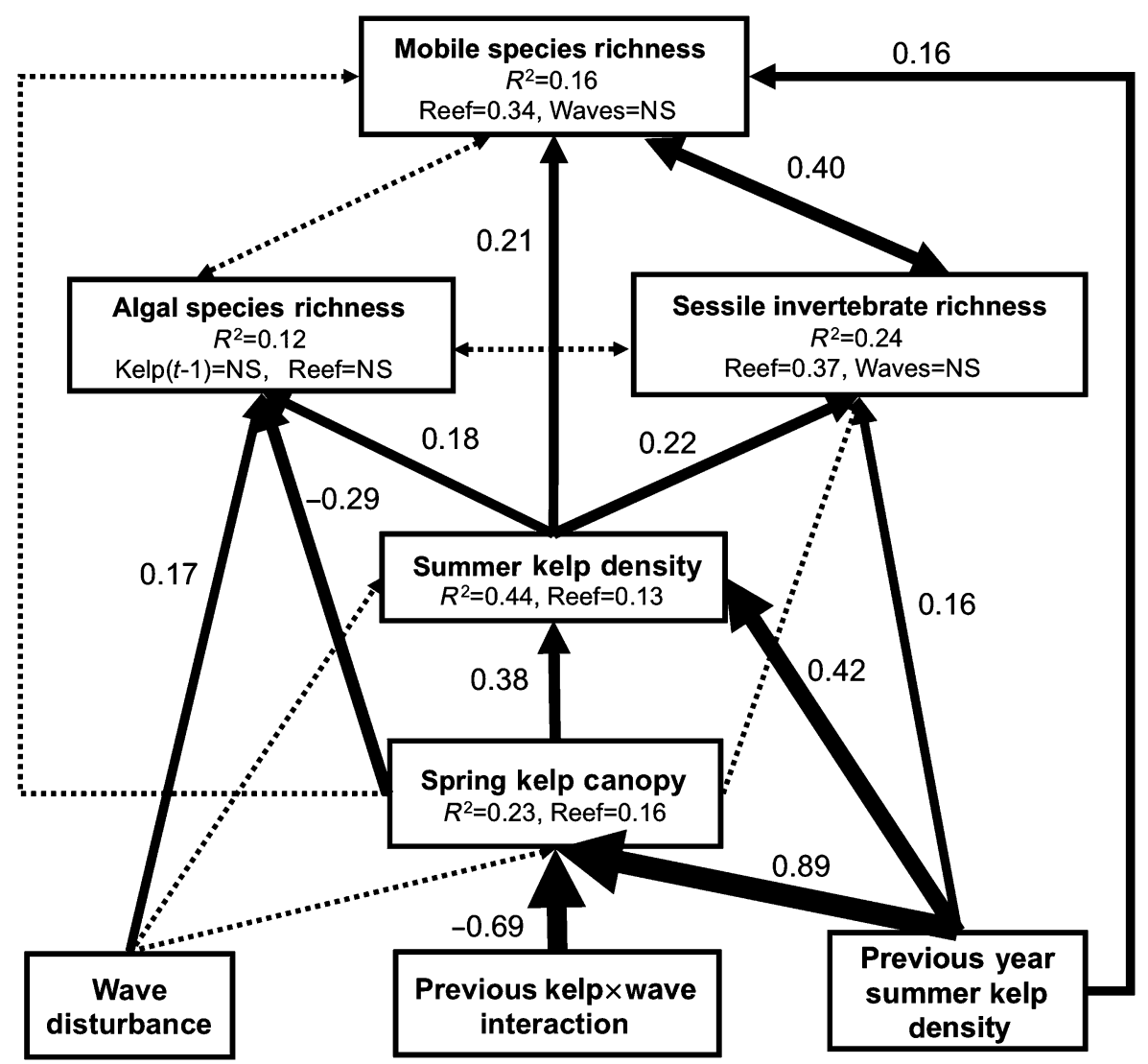

Fig. 3 Path diagrams showing how algal, sessile invertebrate, and mobile species richness are associated with winter wave disturbance from storms and the abundance of kelp in the past year. Results are from a fitted structural equation model that adequately reproduces the observed covariance matrix. Solid paths are statistically different from 0 at $P \leq 0.05$. Dashed paths are not. Path widths are proportional to standardized regression coefficients (shown next to each path), and only paths with strong support $(P \leq 0.05)$ are shown. $R^{2}=1$-(residual variance/observed variance) for each variable. Double-headed arrows represent correlated errors between two dependent variables. For clarity, some path coefficients are included in variable boxes rather than being drawn directly on the diagram (e.g., waves $\rightarrow$ mobile species richness). The standardized coefficient between reef cover and each variable is also included in variable boxes rather than being drawn directly.

species richness and kelp loss declined markedly (slope $=-0.002 \pm 0.003 \mathrm{SE}, \quad F=0.359, P=0.571, t$-test for decline in slope $P=0.003$ ) after 2 successive years of kelp removal (i.e., in 2009, the second year of our experiment). The results for species richness were matched by reduction in linkage density, variation in consumer diet, prey richness, and algal richness (Table 2 , supporting information Tables S3 and S4), suggesting that several aspects of food web complexity also declined with repeated disturbance events. The slope for consumer richness in 2008 was positive and indistinguishable from 0 in 2009, but evidence of a decline was only weakly supported ( $P=0.136$, supporting information Table S4). While no relationship between kelp removal and mobile species richness was seen in 2008, the relationship trended negative in 2009 $(P=0.095)$, as predicted. In contrast, mean food chain length and average number of feeding links between species showed no strong trend in either year (Fig. 2, Table 2). Additionally, sessile invertebrate species richness was positively correlated with kelp loss in 2008, opposite of that predicted.

\section{Discussion}

Our results show that, by removing a foundation species from an ecosystem, increasing the frequency of strong kelp-removing storms to at least one every year has the potential to simplify food webs in southern California kelp forests. The agreement between models of long-term data and short-term manipulations for most food web metrics is striking, particularly given that many additional processes not included in the models (e.g., urchin abundance, recruitment fluctuations, etc.) affected response variables in SEMs. We emphasize that our results are likely conservative in 
Table 2 Predicted changes in food web structure from a single vs. multiple storms and observed changes from experimental kelp removal

\begin{tabular}{|c|c|c|c|c|c|}
\hline & $R^{2}$ & $\begin{array}{l}\text { Change due to } \\
\text { single year of } \\
\text { wave disturbance }\end{array}$ & $\begin{array}{l}\text { Difference between single } \\
\text { year and multiple } \\
\text { consecutive years } \\
\text { of wave disturbances }\end{array}$ & $\begin{array}{l}\text { Slope from } \\
2008 \text { removal }\end{array}$ & $\begin{array}{l}\text { Slope from } \\
\text { repeated } \\
2009 \text { removal }\end{array}$ \\
\hline Richness & 0.22 & $3.18 \pm 2.25$ & $-8.68 \pm 2.49$ & $0.027 \pm 0.008^{*}$ & $-0.002 \pm 0.003$ \\
\hline Linkage density & 0.41 & $0.05 \pm 0.04$ & $-0.15 \pm 0.05$ & $0.002 \pm 0.001^{*}$ & $0 \pm 0$ \\
\hline Variation in consumer diet breadth & 0.44 & $1.08 \pm 0.4$ & $-1.51 \pm 0.5$ & $0.011 \pm 0.005^{*}$ & $0.001 \pm 0.002$ \\
\hline Average \# links between two species & 0.16 & $0.04 \pm 0.03$ & $-0.1 \pm 0.04$ & $0 \pm 0$ & $0 \pm 0$ \\
\hline Average food chain length & 0.14 & $0.08 \pm 0.06$ & $-0.22 \pm 0.08$ & $0 \pm 0$ & $0 \pm 0$ \\
\hline Resource species richness & 0.29 & $2.09 \pm 1.49$ & $-7.12 \pm 1.65$ & $0.031 \pm 0.009^{*}$ & $0.001 \pm 0.003$ \\
\hline Primary consumer richness & 0.55 & $0.73 \pm 0.51$ & $-0.59 \pm 0.8$ & $0.004 \pm 0.003^{*}$ & $0 \pm 0.001$ \\
\hline Algae species richness & 0.12 & $5.1 \pm 1.38$ & $-1.37 \pm 0.9$ & $0.013 \pm 0.007^{*}$ & $0.002 \pm 0.002$ \\
\hline Sessile invertebrate species richness & 0.24 & $-0.71 \pm 0.29$ & $-2.13 \pm 0.65$ & $0.013 \pm 0.004^{*}$ & $-0.001 \pm 0.002$ \\
\hline Mobile species richness & 0.16 & $-1.52 \pm 0.66$ & $-1.51 \pm 0.79$ & $0.001 \pm 0.008$ & $-0.003 \pm 0.002$ \\
\hline
\end{tabular}

$R^{2}$ and changes in response variable values ( $\pm 1 \mathrm{SD}$ ) are from structural equation model (SEM) simulations. Results for variables other than richness are from SEMs that include a path from richness to the variable of interest. Richness values of taxonomic and functional groups are from separate SEMs. Slopes $( \pm 1 \mathrm{SE})$ are from regressions between the number of kelp fronds removed in the winter and the variable of interest measured in summer in the eight experimental plots. Bold slopes are statistically different from 0 at the $P \leq 0.1$ level and bold starred slopes were statistically different from 0 at the $P \leq 0.05$ level.
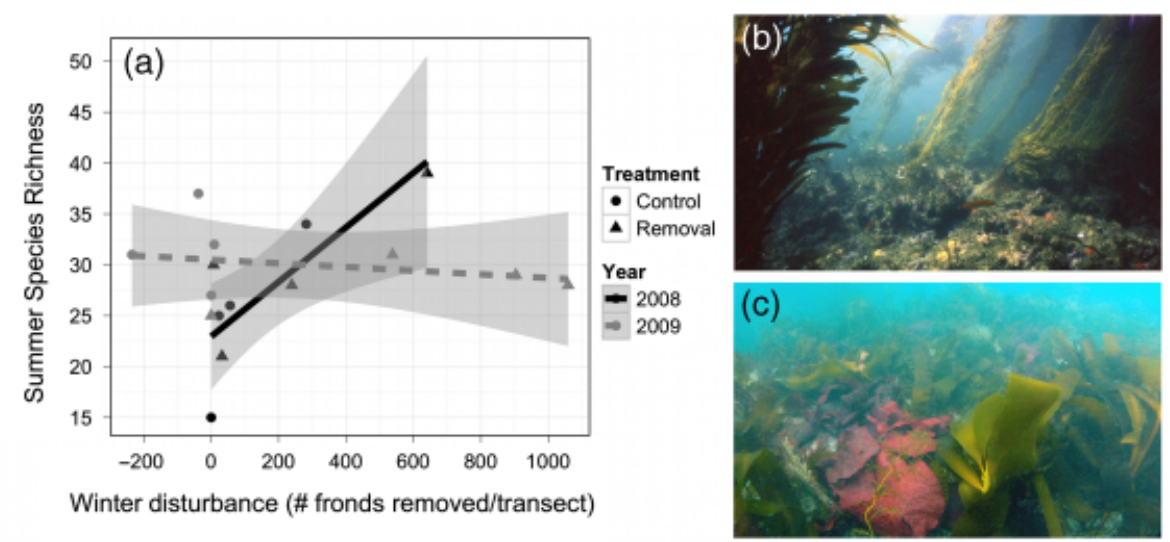

Fig. 4 The contrasting effects of kelp removal on species richness within $2000 \mathrm{~m}^{2}$ plots in 2008 and 2009. Data were collected from $80 \mathrm{~m}^{2}$ transects in the center of plots. (a) The relationship between the number of kelp fronds removed along a transect each winter (via divers or natural disturbance) vs. summer species richness in 2008 (black) and 2009 (grey). Lines represent best fit linear regressions for each year with 95\% CI. Data are drawn from paired removal (triangle) and control (circle) plots on four reefs. (b) Photo of a kelp control plot. (c) Photo of a kelp removal plot in the summer of 2008.

the sense that we did not consider the myriad of other drivers of kelp abundance, such as grazing pressure, nutrient availability, or other local site factors. Experimental results that disagreed with our models may therefore reflect either these additional factors, the effects of the low power of our analysis ( $n=8$ transects) coupled with smaller magnitude of the predicted effects for some metrics (i.e., food chain length and the average food chain length), or both. Even if our predictions are incorrect for these metrics, our general conclusion that frequent large storms will simplify southern California kelp forest food webs is unchanged.

Based on SEMs and simulations, our results suggest a sequence of change in food web structure when confronted with multiple consecutive years of large storms. A single storm hitting a relatively undisturbed kelp forest appears to increase complexity, while concentrating most species at the resource and primary consumer 
trophic levels (Fig. 2, Table 2). At the same time, one storm correlates with a loss in mobile species richness (Fig. 3, Table 2). This occurs despite an increase in average food chain length and linkage density (Fig. 1, Table 2). Together, these three observations suggest that a single storm will result in some species loss at higher trophic levels, but that intraguild predation will also be reduced leading to less reticulate food webs at higher trophic levels. Higher trophic levels do not disappear after initial kelp loss, but rather diversity within these higher trophic levels declines. As storms continue year after year, food webs begin to collapse and the richness of species, whether grouped by trophic level or functional attributes, declines (Table 2). Food chains within a web become shorter. The average food chain length between any two species declines. Overall, our SEM results and simulations show that the system should become simpler and more homogeneous (Table 2). Our experimental results verify these conclusions with respect to overall complexity, although they remain equivocal regarding changes in the trophic height of food webs (Table 2).

We note that giant kelp forests in central California currently experience harsher, more frequent disturbance regimes (Graham et al., 1997). While the food webs of these kelp forests have been poorly studied, results of quantitative surveys show that the understory is dominated by perennial macroalgae and sessile invertebrates, which are relatively resistant to wave disturbance (Foster \& VanBlaricom, 2001). Experimental removals of the perennial understory done to simulate different intensities of disturbance resulted in increased species richness (Reed \& Foster, 1984) suggesting that increases in the intensity of winter storms in central California could alter food webs in much the same way as increases in the frequency of winter storms in southern California. Additional studies of the determinants of food web structure in kelp forests subjected to different disturbance regimes coupled with regional comparisons should provide more robust conclusions regarding the role of wave disturbance in structuring giant kelp forest food webs.

If global change disproportionately affects foundation species, then it may similarly cause shifts in resource availability and physical habitat structure that shape the structure of food webs. In giant kelp forests, increases in the frequency of wave disturbance indirectly alters the environment by removing giant kelp, thereby affecting light, hydrodynamics and the three-dimensional structure of the habitat (reviewed in Graham et al., 2007). Elevated resources resulting from the loss of giant kelp have been shown to enhance the diversity and production of understory algae (Reed \& Foster, 1984; Arkema et al., 2009; Miller et al., 2011) and undoubtedly led to the increases in algal richness revealed in our analyses. Such increases initially stimulated primary consumer diversity (Fig. 2), likely due to a bottom-up diversity cascade (Dyer \& Letourneau, 2003). The increase in algal richness and concomitant increase in primary consumer richness that we observed drove changes in food web complexity after a single disturbance even as mobile species richness declined (Fig. 3, Table 2). Intriguingly, the decline in mobile species richness, likely indicating a loss of diversity at higher trophic levels given the net increase in mobile consumers (Fig. 2), led to an initial gain in food chain length typically associated with a gain in predator diversity (Pimm \& Kitching, 1987; Marks et al., 2000; McHugh et al., 2010), suggesting a greater need to understand food chain length in systems with intraguild predation. When considered collectively our results support the argument that the effects of climate change on species richness are mediated by different processes at different trophic levels (Wootton, 1998).

While our results focus on the structure of kelp forest food webs, based on our current understanding of the link between food web structure and function, we hypothesize that these changes may translate to altered ecological function. There is a growing recognition that the structure of food webs can influence their productivity (Cardinale et al., 2006; Duffy et al., 2007), longterm stability (McCann et al., 1998), and resilience to further extinctions (Dunne et al., 2002; Roopnarine et al., 2007). This change in function may even feed back to further alter kelp forest food web structure. For example, decreases in the diversity of predators within kelp forests can reduce consumptive and nonconsumptive pressure on herbivores, leading to further decreases in the abundance of giant kelp (Byrnes et al., 2006). This, too, may have contributed to the discrepancy between the results of our simulations and experimental manipulations.

Our work demonstrates that if the annual frequency of severe weather events continues to increase due to climate change (Easterling et al., 2000; Meehl et al., 2000), impacts on structure forming foundation species (e.g., coral, seagrasses, trees) may fundamentally alter food web structure. Recovery of foundation species can then be stymied by climate change's effect on their physiology (Wernberg et al., 2010), expansions in the range of novel predators (Ling, 2008), and can be further reduced by various human caused disturbances (Ling et al., 2009). As such there is a compelling need to understand how increases in the frequency of climatedriven disturbances cascade through foundation species to food webs and, ultimately, to changes in the function of whole ecosystems. 


\section{Acknowledgements}

We thank C. Nelson, S. Harrer, M. Anghera, B. Mardian, C. Donahue, K. Arkema, A. Rassweiler, and countless SBC LTER undergraduate students for collection of data in the field. P. Dayton, J. Watanabe, S. Anderson, J. Engle, M. Love, L. Allen, and M. Steele provided essential feedback on our food web. Funding was provided by the US National Science Foundation in support of the SBC LTER and by the NASA Interdisciplinary Science program. M. Graham, M. O'Connor, K. Edwards, G. Rodriguez, and D. Okamoto, and one anonymous reviewer provided valuable comments on the manuscript.

\section{References}

Adams J, Smith MD, Gillespie A (1993) Imaging spectroscopy: interpretation based on spectral mixture analysis. Remote Geochemical Analysis: Elemental and Mineralogical Composition, 7, 145-166.

Arkema KK, Reed DC, Schroeter SC (2009) Direct and indirect effects of giant kelp determine benthic community structure and dynamics. Ecology, 90, 3126-3137.

Baugh W, Groeneveld D (2008) Empirical proof of the empirical line. International Journal of Remote Sensing, 29, 665-672.

Bollen KA (1989) Structural Equations with Latent Variables. Wiley, New York

Briand F (1983) Environmental control of food web structure. Ecology, 64, 253-263.

Briand F, Cohen JE (1987) Environmental correlates of food chain length. Science, 238, 956-960.

Bromirski PD, Flick RE, Cayan DR (2003) Storminess variability along the California coast: 1858-2000. Journal of Climate, 16, 982-993.

Byrnes JE (2010) The sem.additions package for R. Available at http://r-forge. r-project.org/projects/sem-additions/ (accessed November 2010).

Byrnes JE, Stachowicz JJ, Hultgren KM, Hughes AR, Olyarnik SV, Thornber CS (2006) Predator diversity strengthens trophic cascades in kelp forests by modifying herbivore behavior. Ecology Letters, 9, 61-71.

Cardinale BJ, Srivastava DS, Duffy JE, Wright JP, Downing AL, Sankaran M, Jouseau C (2006) Effects of biodiversity on the functioning of trophic groups and ecosystems. Nature, 443, 989-992.

Connell JH (1978) Diversity in tropical rain forests and coral reefs. Science, 199, 1302-1310.

Dayton PK (1985) Ecology of kelp communities. Annual Review of Ecology and Systematics, 16, 215-245.

Dayton PK, Currie V, Gerrodette T, Keller BD, Rosenthal R, Ven Tresca D (1984) Patch dynamics and stability of some California kelp communities. Ecological Monographs, 54, 253-290.

Denny MW, Helmuth B, Leonard GH, Harley CDG, Hunt LJH, Nelson EK (2004) Quantifying scale in ecology: lessons from a wave-swept shore. Ecological Monographs, 74, 513-532.

Douglass JG, Duffy JE, Bruno JF (2008) Herbivore and predator diversity interactively affect ecosystem properties in an experimental marine community. Ecology Letters, 11, 598-608.

Duffy JE, Cardinale BJ, France KE, Mcintyre PB, Thebault E, Loreau M (2007) The functional role of biodiversity in ecosystems: incorporating trophic complexity. Ecology Letters, 10, 522-538

Dunne JA, Williams RJ, Martinez ND (2002) Network structure and biodiversity loss in food webs: robustness increases with connectance. Ecology Letters, 5, 558-567.

Dyer LA, Letourneau D (2003) Top-down and bottom-up diversity cascades in detrital vs. living food webs. Ecology Letters, 6, 60-68.

Easterling DR, Meehl GA, Parmesan C, Changnon SA, Karl TR, Mearns LO (2000) Climate extremes: observations, modeling, and impacts. Science, 289, 2068-2074.

Foster MS, Schiel DR (1985) The Ecology of Giant Kelp Forests in California: A Community Profile. Fish and Wildlife Service, U.S. Department of the Interior, Washington, DC.

Foster MS, VanBlaricom GR (2001) Spatial variation in kelp forest communities along the Big Sur coast of central California, USA. Cryptogamie Algologie, 22, $173-186$

Fox J (2006) Structural equation modeling with the sem package in R. Structural Equation Modeling, 13, 465-486.

Furby S, Campbell N (2001) Calibrating images from different dates to 'like-value' digital counts. Remote Sensing of Environment, 77, 186-196.

Gamfeldt L, Hillebrand H, Jonsson PR (2005) Species richness changes across two trophic levels simultaneously affect prey and consumer biomass. Ecology Letters, 8 696-703.
Gelman A, Hill J (2006) Data Analysis Using Regression and Multilevel/Hierarchical Models. Cambridge University Press, Cambridge.

Graham MH (2004) Effects of local deforestation on the diversity and structure of Southern California giant kelp forest food webs. Ecosystems, 7, 341-357.

Graham MH, Harrold C, Lisin S, Light K, Watanabe JM, Foster MS (1997) Population dynamics of giant kelp Macrocystis pyrifera along a wave exposure gradient. Marine Ecology Progress Series, 148, 269-279.

Graham MH, Vasquez JA, Buschmann AH (2007) Global ecology of the giant kelp Macrocystis: from ecotypes to ecosystems. Oceanography and Marine Biology Annual Review, 45, 39-88.

Graham NE, Diaz HF (2001) Evidence for intensification of North Pacific winter cyclones since 1948. Bulletin of the American Meteorological Society, 82, 1869-1893.

Hobson ES, Chess JR (1986) Relationships among fishes and their prey in a nearshore sand community off southern California. Environmental Biology of Fishes, 17, 201-226.

Hobson ES, Chess JR (2001) Influence of trophic relations on form and behavior among fishes and benthic invertebrates in some California marine communities. Environmental Biology of Fishes, 60, 411-457.

Hughes AR, Byrnes JE, Kimbro DL, Stachowicz JJ (2007) Reciprocal relationships and potential feedbacks between biodiversity and disturbance. Ecology Letters, 10, 849-864

Lee D, Storey J, Choate M, Hayes R (2004) Four years of Landsat-7 on-orbit geometric calibration and performance. IEEE Transactions on Geoscience and Remote Sensing, 42, 2786-2795.

Limbaugh C (1955) Fish Life in the Kelp Beds and the Effects of Kelp Harvesting. University of California, San Diego.

Ling S (2008) Range expansion of a habitat-modifying species leads to loss of taxonomic diversity: a new and impoverished reef state. Oecologia, 156, 883-894.

Ling SD, Johnson CR, Frusher SD, Ridgway KR (2009) Overfishing reduces resilience of kelp beds to climate-driven catastrophic phase shift. Proceedings of the National Academy of Sciences, 106, 22341-22345.

Mackey RL, Currie DJ (2001) The diversity-disturbance relationship: is it generally strong and peaked? Ecology, 82, 3479-3492.

Marks JC, Power ME, Parker MS (2000) Flood disturbance, algal productivity, and interannual variation in food chain length. Oikos, 90, 20-27.

McCann K, Hastings A, Huxel GR (1998) Weak trophic interactions and the balance of nature. Nature, 395, 794-798.

McHugh PA, McIntosh AR, Jellyman PG (2010) Dual influences of ecosystem size and disturbance on food chain length in streams. Ecology Letters, 13, 881-890.

Meehl GA, Stocker TF, Collins WD et al. (2007) Global climate projections. In: Climate Change 2007: The Physical Science Basis. Contribution of Working Group I to the Fourth Assessment Report of the Intergovernmental Panel on Climate Change (eds Solomon S, Qin D, Manning M, Chen Z, Marquis M, Averyt KB, Tignor M, Miller HL), pp. 747845, Cambridge University Press, Cambridge, UK.

Meehl GA, Zwiers F, Evans J, Knutson T, Mearns L, Whetton P (2000) Trends in extreme weather and climate events: issues related to modeling extremes in projections of future climate change. Bulletin of the American Meteorological Society, 81, 427-436.

Menge BA, Sutherland JP (1987) Community regulation: variation in disturbance, competition, and predation in relation to environmental stress and recruitment. American Naturalist, 130, 730-757.

Miller RJ, Reed DC, Brzezinski MA (2011) Partitioning of primary production among giant kelp (Macrocystis pyrifera), macroalgae, and phytoplankton on a temperate reef. Limnology and Oceanography, 56, 119-132.

Oksanen L, Fretwell SD, Arruda J, Niemela P (1981) Exploitation ecosystems in gradients of primary productivity. The American Naturalist, 118, 240-261.

Pimm SL, Kitching RL (1987) The determinants of food chain lengths. Oikos, 50, 302-307

Post DM, Pace ML, Hairston NG (2000) Ecosystem size determines food-chain length in lakes. Nature, 405, 1047-1049.

Quast J (1968) Observations on the food of the kelp-bed fishes. In: Utilization of KelpBed Resources in Southern California, Fish Bulletin (eds North WJ, Hubbs CL), pp. 109 142. California Department of Fish and Game, Sacramento, CA.

Reed DC, Brzezinski MA (2009) Kelp forests. In: The Management of Natural Coastal Carbon Sinks (eds Laffoley D, Grimsditch G), pp. 30-37. IUCN, Gland, Switzerland.

Reed DC, Ebeling AW, Anderson TW, Anghera M (1996) Differential reproductive responses to fluctuating resources in two seaweeds with different reproductive strategies. Ecology, 77, 300-316.

Reed DC, Foster MS (1984) The effects of canopy shading on algal recruitment and growth in a giant kelp forest. Ecology, 65, 937-948. 
Reed DC, Rassweiler A, Arkema KK (2008) Biomass rather than growth rate determines variation in net primary production by giant kelp. Ecology, 89, 2493-2505.

Roberts D, Gardner M, Church R, Ustin S, Scheer G, Green R (1998) Mapping chaparral in the Santa Monica Mountains using multiple endmember spectral mixture models. Remote Sensing of Environment, 65, 267-279.

Roopnarine PD, Angielczyk KD, Wang SC, Hertog R (2007) Trophic network models explain instability of Early Triassic terrestrial communities. Proceedings of the Royal Society B: Biological Sciences, 274, 2077-2086.

Ruggiero P, Komar PD, Allan JC (2010) Increasing wave heights and extreme value projections: the wave climate of the U.S. Pacific Northwest. Coastal Engineering, 57, 539-552.

Schoener TW (1989) Food webs from the small to the large: the Robert H. MacArthur Award Lecture. Ecology, 70, 1559-1589.

Thompson RM, Townsend CR (1999) The effect of seasonal variation on the community structure and food-web attributes of two streams: implications for food-web science. Oikos, $87,75-88$.

Thompson RM, Townsend CR (2005) Food web topology varies with spatial scale in a patchy environment. Ecology, 86, 1916-1925.

Vermaat JE, Dunne JA, Gilbert AJ (2009) Major dimensions in food-web structure properties. Ecology, 90, 278-282.

Walters AW, Post DM (2008) An experimental disturbance alters fish size structure but not food chain length in streams. Ecology, 89, 3261-3267.

Wernberg T, Thomsen MS, Tuya F, Kendrick GA, Staehr PA, Toohey BD (2010) Decreasing resilience of kelp beds along a latitudinal temperature gradient: potential implications for a warmer future. Ecology Letters, 13, 685-694.

Wootton JT (1998) Effects of disturbance on species diversity: a multitrophic perspective. The American Naturalist, 152, 803-825.

\section{Supporting Information}

Additional Supporting Information may be found in the online version of this article:

Appendix S1. Kelp Forest Food Web Assembly.

Table S1. Feeding relationships for species sampled by the Santa Barbara Coastal Long Term Ecological Research (SBC LTER) project.

Table S2. Coefficient values, standard errors, z-scores, and standardized path coefficients for each fitted structural equation model.

Table S3. The results of regressions evaluating whether the winter decrease in kelp in experimental plots was a predictor of different response variables in 2008 and 2009.

Table S4. Statistical comparison between slopes in 2008 and 2009.

Please note: Wiley-Blackwell are not responsible for the content or functionality of any supporting materials supplied by the authors. Any queries (other than missing material) should be directed to the corresponding author for the article. 